\title{
Produção e qualidade da melancia submetida a adubação nitrogenada
}

\author{
Márcio M. Barros ${ }^{1}$, Wellington F. Araújo를 Leandro T. B. C. Neves ${ }^{3}$, \\ André J. de $\operatorname{Campos}^{4} \&$ Jéssica M. Tosin ${ }^{5}$
}

\begin{abstract}
RESU M O
Propôs-se, neste trabalho, avaliar o efeito da aplicação de diferentes doses de nitrogênio sobre a produção e qualidade de melancia 'Crimson Sweet'. Conduziu-se esta pesquisa na área experimental da U niversidade Federal de Roraima, Boa Vista, RR, no período de janeiro a abril de 2010. 0 delineamento experimental utilizado foi o de blocos inteiramente casualizados, com 4 repetições. Os tratamentos consistiram de 5 níveis de nitrogênio $\left(50,100,150,200\right.$ e $\left.250 \mathrm{~kg} \mathrm{ha}^{-1} \mathrm{de} \mathrm{N}\right)$ aplicados na forma de ureia, de modo convencional. A produção comercial máxima obtida foi de $40.428 \mathrm{~kg} \mathrm{ha}^{-1} \mathrm{com} 144,76 \mathrm{~kg} \mathrm{ha}^{-1}$ de $\mathrm{N}$. Referente à qualidade dos frutos, o pH não foi influenciado pelos tratamentos, apresentando média de 5,34. A relação comprimento/diâmetro e a espessura da casca também não sofreram influência dos tratamentos enquanto a firmeza do fruto, o conteúdo de sólidos solúveis (SS), a acidez titulável (AT), o conteúdo de açúcares (redutores, não redutores e totais), o teor de ácido ascórbico e a relação SS/AT, foram influenciados pelos níveis de $\mathrm{N}$.
\end{abstract}

Palavras-chave: Citrullus lanatus, pós-colheita, caracterização, produtividade

\section{Production and quality of watermelon under nitrogen fertilization}

\begin{abstract}
AB STRACT
The aim of this study was to evaluate the effect of different rates of nitrogen on production and quality of watermelon 'Crimson Sweet'. This research was conducted in the experimental area of the Federal U niversity of Roraima, Boa Vista, from January to A pril 2010. The experimental design was in randomized blocks with 4 replications. The treatments consisted of 5 levels of nitrogen $(50,100,150,200$ and 250 $\mathrm{kg} \mathrm{ha}^{-1} \mathrm{~N}$ ) applied as urea in a conventional manner. The results showed that the maximum commercial production was $40,428 \mathrm{~kg} \mathrm{ha}^{-1}$ with $144.76 \mathrm{~kg} \mathrm{ha}^{-1} \mathrm{~N}$. Regarding the fruit quality, the $\mathrm{pH}$ was not affected by treatments, showing mean value of 5.34. The length/diameter ratio and bark thickness also were not influenced by the treatments, while the firmness, content of soluble solids (SS), titratable acidity (TA), content of sugars (reducing, non reducing and total), the ascorbic acid content and the ratio SS/TA were not influenced by $\mathrm{N}$ levels.
\end{abstract}

Key words: Citrullus lanatus, postharvest, characterization, productivity

\footnotetext{
${ }^{1}$ M estrando/Bolsista da Capes no Programa de Pós-G raduação em Agronomia, U FRR, BR 174, KM 12 s/n, CEP 69301-970, Boa Vista, RR. E-mail: mesquita_barros@hotmail.com

2 DSEA/UFRR. E-mail: wellington@cca.ufrr.br

${ }^{3}$ DFT/UFRR, Pós-D outorado in Food Science. Email: rapelbtu@hotmail.com

${ }^{4}$ U EG/U nU CET, BR 153, 3105, CEP 75132-400, Campus Henrique Santillo, Anápolis/GO. E-mail: andre.jose@ueg.br

${ }^{5}$ G raduanda em Agronomia/U FRR, Bolsista de Iniciação ao Extensionismo do CN Pq. E-mail: jessica.mtosin@hotmail.com
} 


\section{INTRODUÇÃO}

A melancia (Citrullus lanatus Thumb. Mansf.) é cultivada em várias regiões do território brasileiro, destacando-se nos Estados do Nordeste (Bahia, Pernambuco, Maranhão e Rio Grande do Norte); Sudeste (São Paulo), Sul (Santa Catarina e Rio Grande do Sul) e no Centro-Oeste (Goiás). Cultivada também entre os agricultores, a melancieira é uma espécie olerícola com excelente adaptação em Roraima 2007) onde a cultura teve impulso significativo a partir da década de 90 , mostrando uma crescente evolução pela excelente adaptação, em virtude das condições edafoclimáticas locais, propiciando cultivos praticamente o ano todo (Medeiros \& Halfeld-Vieira, 2007). A produtividade da melancia em Roraima foi de $8.024 \mathrm{~kg}$ $\mathrm{ha}^{-1}$ em 2009 (IBGE, 2009), muito abaixo do potencial de 70.000 $\mathrm{kg} \mathrm{ha}^{-1}$ devido à baixa tecnologia adotada pelos produtores a qual está relacionada principalmente ao manejo inadequado da irrigação e à adubação. Estima-se, entretanto, que com a adoção de tecnologia adequada a produção possa triplicar (Medeiros \& Halfeld-Vieira, 2007).

A cultura da melancia tem, na nutrição mineral um dos fatores que contribuem diretamente sobre a produtividade e qualidade dos frutos. $\mathrm{O}$ nitrogênio é um nutriente essencial para se obter aumento de produtividade haja vista que apresenta função estrutural importante, sendo componentes de aminoácidos, amidas, proteínas, ácidos nucléicos, nucleotídeos, coenzimas, hexoaminas, clorofila e metabólitos secundários, que estão relacionados com a defesa da planta e com os processos bioquímicos e fisiológicos mais importantes que ocorrem na planta, tais como fotossíntese, respiração, desenvolvimento e atividade das raízes, absorção iônica de outros nutrientes, crescimento e diferenciação celular (Taiz \& Zeiger, 2004).

A nutrição mineral tem contribuição relevante sobre qualidade dos frutos; no entanto, nem sempre se consegue solucionar o desafio de aumentar a produção sem afetar a qualidade dos frutos. Aumentos na produção, proporcionados pelo emprego de fertilizantes, devem ser acompanhados pelo aumento ou manutenção da qualidade dos frutos produzidos, a fim de que eles possam atender ao mercado consumidor, de forma satisfatória (Granjeiro \& Cecílio Filho, 2004; Medeiros, 2008).

Desta forma, o objetivo do trabalho foi avaliar o efeito da aplicação de nitrogênio sobre os componentes de produção e qualidade de frutos da melancia 'Crimson Sweet', nas condições de savana de Boa Vista, Roraima.

\section{Material e MÉTOdos}

O experimento foi conduzido no período de janeiro a abril de 2010, em área de savana (cerrado) do Centro de Ciências Agrárias da Universidade Federal de Roraima (CCA/UFRR) situada no município de Boa Vista, estado de Roraima, cujas coordenadas de referência são: $2^{\circ} 49^{\prime} 17^{\prime \prime}$ N, 60 39' 45" W e 90 $\mathrm{m}$ de altitude. O clima da região, de acordo com a classificação de Köppen, é do tipo Awi, tropical chuvoso, com precipitação média anual de $1.678 \mathrm{~mm}$, umidade relativa do ar em torno de
$70 \%$ e temperatura média anual de $27,4^{\circ} \mathrm{C}$ (Araújo et al., 2001). A fitofisionomia é do tipo savana gramíneo-lenhosa.

$\mathrm{O}$ experimento foi conduzido em Latossolo amarelo distrocoeso, com as seguintes características na camada de 0 $20 \mathrm{~cm}: \mathrm{pH}$ (água) $=5,5 ; \mathrm{P}=6,5 \mathrm{mg} \mathrm{dm}^{-3} ; \mathrm{K}^{+}=0,04 \mathrm{cmol}_{\mathrm{c}} \mathrm{dm}^{-3}$; $\mathrm{Ca}^{2+}=0,53 \mathrm{cmol}_{\mathrm{c}} \mathrm{dm}^{-3} ; \mathrm{Mg}^{2+}=0,1 \mathrm{cmol}_{\mathrm{c}} \mathrm{dm}^{-3} ; \mathrm{SB}=0,64$ $\mathrm{cmol}_{\mathrm{c}} \mathrm{dm}^{-3} ; \mathrm{H}+\mathrm{Al}^{\mathrm{c}+}=1,78 \mathrm{cmol}_{\mathrm{c}} \mathrm{dm}^{-3} ; \mathrm{V}=26,4 \%$; areia $=64,9 \%$; silte $=13,1 \%$ e argila $=22 \%$.

Os tratamentos consistiram da aplicação de cinco níveis de nitrogênio $\left(50,100,150,200\right.$ e $\left.250 \mathrm{~kg} \mathrm{ha}^{-1}\right)$, na forma de ureia, parcelados igualmente e aplicados de três vezes, primeiro na adubação de fundação, junto com os outros adubos e as demais aplicações de cobertura de N e K aos 15 e 30 DAE (dias após a emergência).

A parcela experimental foi constituída de três fileiras de $8 \mathrm{~m}$ de comprimento contendo 8 plantas com espaçamento entre linhas de 3,0 e 1,0 m entre plantas, medindo $48 \mathrm{~m}^{2}$. Para efeito de coleta de dados considerou-se a linha central, com o total de 6 plantas, eliminando-se 1,0 m nas extremidades da fileira cuja área útil foi de $18 \mathrm{~m}^{2}$.

A melancia cv. Crimson Sweet foi semeada diretamente no campo, em covas, medindo $0,4 \times 0,4$ x 0,4 m de largura, comprimento e profundidade, respectivamente, colocando-se 3 sementes por cova e se deixando apenas uma planta, por ocasião do desbaste aos 15 DAE.

A irrigação foi feita por gotejamento com emissores espaçados $0,5 \mathrm{~m}$ e com vazão nominal de $4,5 \mathrm{~L} \mathrm{~h}^{-1}$ a uma pressão de serviço de $147 \mathrm{kPa}$. A reposição de água ocorreu a cada dois dias, tomando-se como base $95 \%$ da evaporação do tanque Classe A, conforme resultados alcançados por Azevedo et al. (2005). Durante o período experimental os dados climáticos foram monitorados diariamente por uma estação automática localizada a $200 \mathrm{~m}$ do experimento. Observaram-se temperatura média do ar de $28,2^{\circ} \mathrm{C}$, umidade relativa do ar média de $70,5 \%$, velocidade média do vento de $2,0 \mathrm{~m} \mathrm{~s}^{-1} \mathrm{e}$ precipitações totais de $190 \mathrm{~mm}$, que ocorreram durante a instalação do experimento estendendo-se até o início da fase vegetativa; enfim, os tratos culturais realizados durante o ciclo da cultura foram: desbaste de plantas, capinas, penteamento das ramas e controle de pragas e doenças.

Três colheitas foram realizadas, a primeira aos 80 DAE, quando o ponto de colheita foi identificado pela observação da gavinha seca mais próxima ao fruto e do pedúnculo, a mudança de coloração dos frutos, sobretudo na parte apoiada no chão, passando de branco a amarelo-claro e teor de sólidos solúveis dos frutos de no mínimo $10{ }^{\circ} \mathrm{Brix}$, medido com refratômetro digital.

As avaliações envolvendo os componentes de produção foram realizadas no período correspondente às três colheitas, descartados os frutos com deformidades, manchas, injúrias ou qualquer tipo de dano aparente e, como componentes de produção, foram avaliados:

Número de frutos por hectare: obtido pela contagem de frutos da área útil da parcela e convertido para frutos $\mathrm{ha}^{-1}$;

Produtividade: determinada a partir do somatório dos frutos da área útil da parcela, expressa em $\mathrm{kg} \mathrm{ha}^{-1}$; 
Massa fresca dos frutos: obtida dividindo-se a massa total de frutos pelo número de frutos totais, expressa em $\mathrm{kg}$.

As avaliações envolvendo os componentes de qualidade da melancia foram realizadas coletando-se dados referentes aos dois frutos provenientes da primeira colheita, escolhidos de forma aleatória e livres de deformidades como manchas, injúrias ou qualquer tipo de dano aparente. Obteve-se a coleta dos dados no Laboratório de Tecnologia de Alimentos do Centro de Ciências Agrárias da Universidade Federal de Roraima; aqui foram avalidos, como componentes de qualidade:

SS - sólidos solúveis: obtidos a partir da polpa, por refratometria com correção da temperatura, conforme metodologia descrita pelo IAL (2008); os resultados foram expressos em ${ }^{\circ}$ Brix;

AT - acidez titulável: obtida a partir da polpa, determinada por titulometria de neutralização, pela titulação de $10 \mathrm{~g}$ de polpa, homogeneizada e diluída para $100 \mathrm{~mL}$ em água destilada, com solução padronizada de $\mathrm{NaOH}$ a $1 \mathrm{~N}$, com ponto de viragem no pH 8,2, de conformidade com o método da IAL (2008); os resultados foram expressos em $\mathrm{g}$ de ácido cítrico $100 \mathrm{~g}^{-1} \mathrm{de}$ polpa $-0,1 \mathrm{~N}(\mathrm{NaOH})$

pH - potencial hidrogeniônico: obtido a partir da polpa, determinado em amostras constituídas de $10 \mathrm{~g}$ de polpa em 100 $\mathrm{mL}$ de água destilada, utilizando-se do pHgâmetro marca Hanna Instruments modelo pH 300, em que os resultados foram expressos em unidades de $\mathrm{pH}$, com base no método da IAL (2008).

AR - açúcares redutores: obtidos a partir da polpa, determinados segundo a metodologia de Nelson (1944) e expressos em porcentagem (\%) de açúcares.

ANR - açúcares não redutores: obtidos a partir da polpa, determinados segundo a metodologia de Nelson (1944) e expressos em porcentagem (\%) de açúcares.

AST - açúcares solúveis totais: obtidos a partir da polpa, determinados segundo a metodologia de Nelson (1944) e expressos em porcentagem (\%) de açúcares.

Índice de maturação - SS/AT: obtido pelo quociente relacionado aos sólidos solúveis/acidez titulável;

Ácido ascórbico (vitamina C): obtido a partir da polpa e determinado segundo método de Carvalho et al. (1990), que se baseia na redução do indicador 2,6 - diclorobenzenoindolfenol (DCFI) pelo ácido ascórbico; esses resultados foram expressos em mg $100 \mathrm{~mL}^{-1}$ de polpa.

Teor de pectina total: obtido a partir da polpa, extraída seguindo a técnica adaptada por McCready \& McCoomb (1952) e determinada colorimetricamente pela reação com carbazol. Os conteúdos foram expressos em \% de ácido galacturônico $100 \mathrm{~g}^{-1}$ de polpa.

Espessura da casca: obtida pela medida da casca do fruto com o auxílio de paquímetro graduado manual; suas medidas foram expressas em $\mathrm{mm}$.

Índice de formato de fruto: obtido pela razão das medidas das seções verticais (comprimento) e horizontais (diâmetro) dos frutos; o comprimento do fruto (medido no sentido transversal na região equatorial) (C) e o diâmetro (D) de fruto (medido na região seccionada) foram obtidos através do uso de uma fita graduada em $\mathrm{mm}$.
Firmeza de polpa: foi obtida a partir da polpa, utilizando-se texturômetro manual, equipado com ponta de $6 \mathrm{~mm}$ de diâmetro, em que os resultados foram expressos em Newtons (N).

O delineamento estatístico utilizado foi o de blocos casualizados, com cinco tratamentos e quatro repetições; os resultados foram submetidos à análise de variância e análise de regressão, testados os modelos linear e polinomial quadrático. As equações de regressão foram escolhidas com base na significância dos coeficientes de regressão, a 1 e $5 \%$ de probabilidade, pelo teste $\mathrm{Fe}$, no maior valor de significância, pela análise estatística e no coeficiente de determinação $\mathrm{R}^{2}$. Os testes estatísticos foram realizados com o auxílio do programa estatístico SISVAR versão 5.1 (Ferreira, 2003).

\section{RESULTADOS E DISCUSSÃO}

Os valores de produtividade em função dos níveis de nitrogênio, quando se obteve um valor máximo médio de produtividade de $40.428 \mathrm{~kg} \mathrm{ha}^{-1} \mathrm{com} 144,76 \mathrm{~kg} \mathrm{ha}^{-1} \mathrm{de} \mathrm{N}$, se encontram na Tabela 1. Resultados semelhantes foram obtidos por outros autores; entretanto, há divergências nos níveis de nitrogênio utilizados e nos valores de produtividades a serem alcançados. A produtividade alcançada foi superior à observada por Mousinho et al. (2003) quando também obtiveram, por adubação convencional, produção comercial máxima de 30.806 $\mathrm{kg} \mathrm{ha}^{-1}$ com a dose de 222,1 $\mathrm{kg} \mathrm{ha}^{-1}$ de nitrogênio, embora inferior à produtividade de $66.770 \mathrm{~kg} \mathrm{ha}^{-1}$ utilizando-se $104,5 \mathrm{~kg} \mathrm{ha}^{-1} \mathrm{de}$ N, via fertirrigação, obtida por Andrade Júnior et al. (2006), supostamente pela aplicação de $\mathrm{N}$ obedecendo à marcha de absorção do elemento, o que maximiza seu uso pela cultura.

Tabela 1. Resumo da análise de variância dos dados para sólidos solúveis (SS), acidez titulável (AT), potencial hidrogeniônico $(\mathrm{pH})$, açúcares redutores (AR), açúcares não redutores (ANR), açúcares solúveis totais (AST), índice de maturação (SS/AT), teor de pectina total (PEC TOTAL), ácido ascórbico (AC. ASC.), espessura da casca (ESP CASC), relação comprimento/diâmetro (C/D ) e firmeza de polpa (FIRM)

\begin{tabular}{lccc}
\hline FV & QM & CV (\%) & Média geral \\
SS & $6,86^{* *}$ & 3,52 & 10,61 \\
AT & $0,007^{* *}$ & 1,83 & 1,51 \\
pH & $0,03^{\text {ns }}$ & 2,98 & 5,63 \\
AR & $5,05^{* *}$ & 3,06 & 6,05 \\
ANR & $0,007^{* *}$ & 7,49 & 0,31 \\
AST & $6,15^{* *}$ & 1,84 & 6,37 \\
SS/AT & $0,24^{* *}$ & 1,49 & 6,93 \\
PEC TOTAL & $1114,59^{* *}$ & 0,50 & 409,33 \\
AC. ASC. & $48,09^{* *}$ & 4,75 & 12,35 \\
ESP CASC & $5,49^{\text {ns }}$ & 18,96 & 12,57 \\
C/D & $0,00007^{\text {ns }}$ & 4,62 & 1,06 \\
FIRM & $17,44^{* *}$ & 8,12 & 21,85 \\
\hline ns,${ }^{* * *}$ - não significativo, significativo a nível de 0,05 e 0,01 de probabilidade pelo teste $\mathrm{F}$, \\
respectivamente & & &
\end{tabular}

Em referência à massa fresca dos frutos, um modelo quadrático foi ajustado, obtendo-se um valor máximo de 9,45 $\mathrm{kg}$ por fruto, com 248,5 $\mathrm{kg} \mathrm{ha}^{-1}$ de N (Figura 1B), cujo resultado 
A.

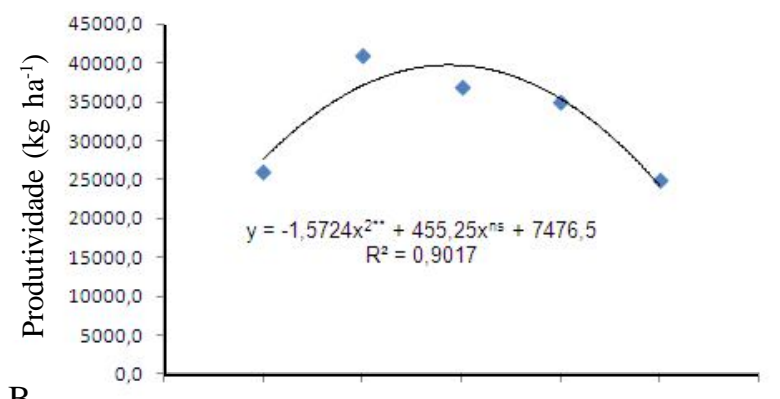

B.

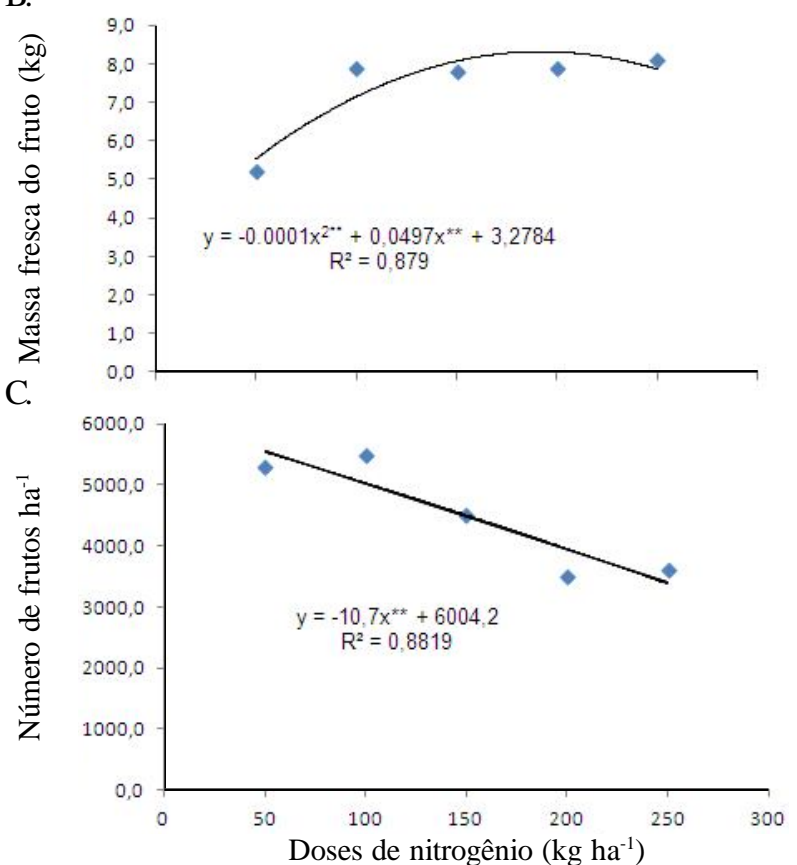

Figura 1. Variação média da produtividade de frutos $\left(\mathrm{kg} \mathrm{ha}^{-1}\right)(\mathrm{A})$, massa fresca do fruto $(\mathrm{kg})(B)$ e número médio de frutos ha-1 (C) de melancia (Citrullus lanatus) em função de níveis de nitrogênio

foi inferior ao observado por Andrade Júnior et al. (2006) que obtiveram frutos com peso de $8,93 \mathrm{~kg}$ por fruto, usando 103 $\mathrm{kg} \mathrm{ha}^{-1} \mathrm{de} \mathrm{N}$, via fertirrigação.

Os níveis crescentes de nitrogênio aumentaram a massa fresca do fruto em detrimento do número de frutos por hectare (Figura 1C), evento devido ao fato de o fruto ser o órgão que acumula maior matéria seca no final do ciclo e ser, também, dreno principal de fotoassimilados (Grangeiro \& Cecílio Filho, 2004; 2005a; 2005b; Vidigal et al., 2009).

Observa-se que o número de frutos por hectare diminui linearmente na medida em que se aumenta a quantidade de nitrogênio, em decorrência da redução da frutificação, corroborando com os resultados obtidos por Garcia \& Sousa (2002) em solos arenosos do Parnaíba, PI.

Com relação aos componentes de qualidade ocorreu significância a nível de $1 \%$ dos componentes de qualidade, exceto $\mathrm{pH}$, espessura de casca e relação comprimento/diâmetro, que não foram significativos dentro dos percentuais estabelecidos de 1 ou $5 \%$ de probabilidade (Tabela 1).

O valor médio e a análise de variância dos sólidos solúveis obtidos a partir da polpa dos frutos de melancia em função dos níveis de adubação nitrogenada estão expostos na Tabela 1. A análise de variância e o modelo quadrático foram significativos a $1 \%$ de probabilidade. Observou-se o máximo valor médio de sólidos solúveis $12,23 \%$, obtido com o nível de $162,75 \mathrm{~kg} \mathrm{ha}^{-1}$ de nitrogênio, reduzindo o valor de ${ }^{\circ} \mathrm{Brix}$ na medida em que se aumentaram os níveis de nitrogênio (Figura 2A).

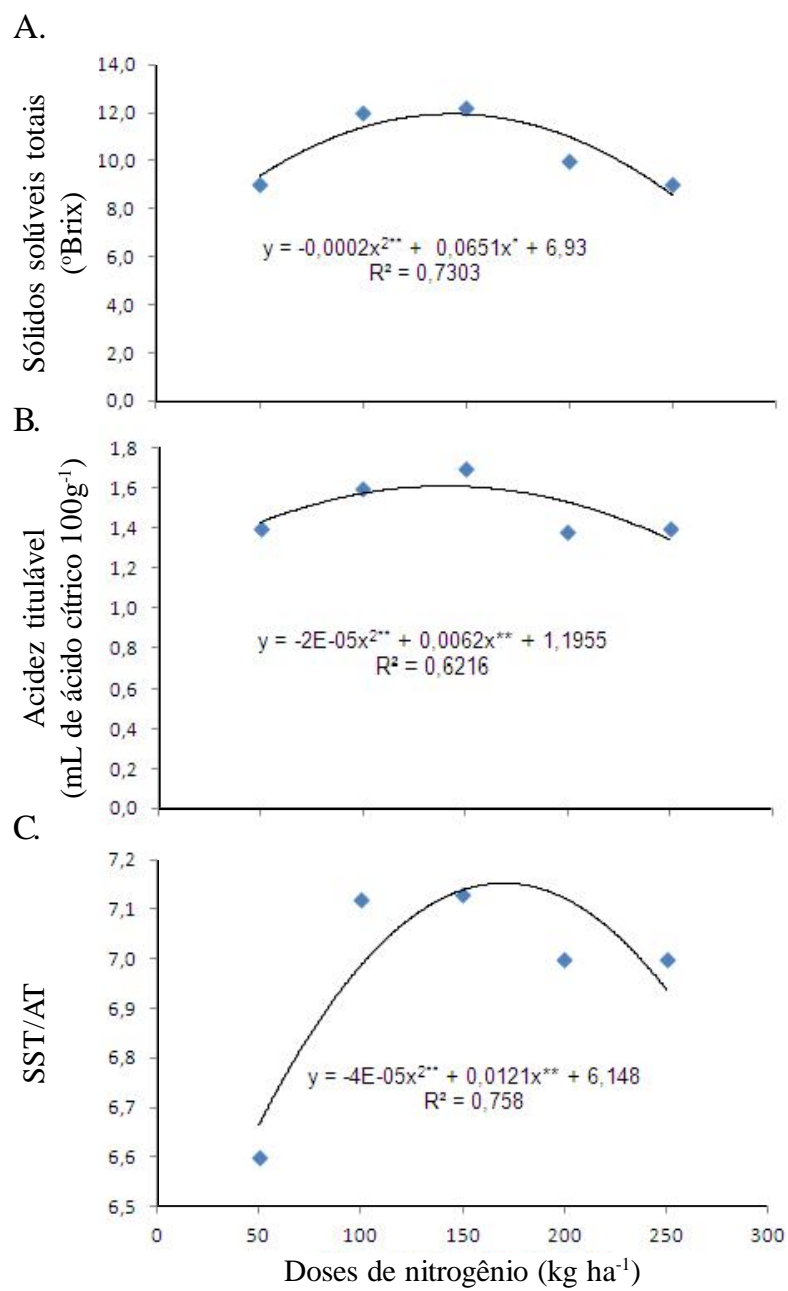

Figura 2. Variação média de sólidos solúveis totais (SST) (A), acidez titulável (g de ácido cítrico $100 \mathrm{~g}^{-1}$ p.f.) (B) e índice de maturação (SST/AT) (C) da polpa de melancia (Citrullus lanatus) em função de níveis de nitrogênio

Os teores de SS em frutos de melancia são bastante desejáveis e de grande aceitação, visto que este índice é considerado parâmetro importante em muitos países, inclusive no Brasil (Bleinroth, 1994); o teor máximo observado está de acordo com as exigências do mercado, que é de $10 \%$ como o mínimo aceitável à comercialização.

Os resultados estão de acordo com os obtidos por Morais et al. (2008) que, estudando efeito de nitrogênio e lâminas de água no Vale do Curu, CE, obtiveram respostas com o modelo quadrático e com valores máximos médios de ${ }^{\circ}$ Brix de 10,27, obtidos com a aplicação de $198 \mathrm{~kg} \mathrm{ha}^{-1}$ de nitrogênio e lâmina de água de $316 \mathrm{~mm}$.

Mousinho et al. (2003) observaram, em Fortaleza, CE, que a aplicação de diferentes doses de nitrogênio variando de 0 a 
$300 \mathrm{~kg} \mathrm{ha}^{-1}$, influenciou os teores de sólidos solúveis dos frutos de melancia reduzindo-os com o aumento do nível. Andrade Júnior et al. (2006) verificaram, trabalhando com diferentes doses de nitrogênio $\left(0,40,80,120\right.$ e $\left.160 \mathrm{~kg} \mathrm{ha}^{-1} \mathrm{de} \mathrm{N}\right)$ na cultura da melancia, que não houve efeito significativo para essa característica; contudo, há trabalhos mostrando que níveis de adubação nitrogenada não exercem efeito sobre o teor de sólidos solúveis com os resultados (Garcia \& Souza, 2002).

De acordo com Villanueva et al. (2004), o acúmulo de açúcar durante o crescimento e desenvolvimento do fruto é de grande importância em virtude da alta correlação existente entre conteúdo de açúcar e qualidade do fruto. Segundo Valantin et al. (2006), a competição por assimilados reduziu o SS; desta forma, o SS, que está diretamente relacionado com o conteúdo de açúcar, constitui bom indicador do adoçamento e, consequentemente, da qualidade, quanto ao sabor do fruto, fato atribuído principalmente à elevação da concentração de sacarose na polpa dos frutos.

Ocorreu resposta quadrática para acidez titulável com significância de $1 \%$, observando-se seu ponto de máxima de $1,67 \mathrm{~g}$ de ácido cítrico $100 \mathrm{~g}^{-1}$ de polpa com adubação no nível de $155 \mathrm{~kg} \mathrm{ha}^{-1}$ de N (Figura 2B). Esses resultados são contrários aos observados por Garcia \& Souza (2002) e Andrade Júnior et al. (2006) em que os autores não constataram efeitos significativos na acidez titulável em melancia, embora os valores médios sejam próximos aos deste experimento.

Purquerio et al. (2003) e Purquerio \& Cecílio Filho (2005), no entanto, observaram que o incremento na concentração de nitrogênio na solução nutritiva promoveu aumento na acidez titulável dos frutos, possivelmente resultado de um atraso da maturação dos frutos de melão, decorrente do maior teor de nitrogênio presente na solução nutritiva. Para um fruto mais palatável, mais importante que a acidez titulável, é a relação desta variável com os sólidos solúveis, definindo o índice de maturação.

O índice de maturação (SS/AT) é uma relação usada para avaliar não só o estado de maturação mas também a palatabilidade dos frutos. No presente trabalho houve efeito significativo ( $p>0,01)$ para o índice de maturação, respondendo de forma quadrática, até o valor máximo estimado de 7,06 para $151,25 \mathrm{~kg} \mathrm{ha}^{-1}$ de $\mathrm{N}$, decrescendo a partir deste ponto, que pode ser explicado em função dos fatores envolvidos, sólidos solúveis e acidez titulável, terem seus valores máximos próximos ao valor da relação (Figura 2C); os resultados são superiores aos encontrados por Garcia \& Sousa (2002), sobremaneira por alterações nos valores encontrados de AT em função dos tratamentos, revelando um valor maior da relação SS/AT, que foi de 4,03, quando do uso de 46,6 $\mathrm{kg} \mathrm{ha}^{-1}$ de $\mathrm{N}$, decrescendo a partir deste nível.

Chitarra \& Chitarra (1990) afirmam que os índices químicos mais utilizados na determinação do ponto de maturação dos frutos, são pH, acidez titulável e sólidos solúveis; os autores ressaltam, ainda, que o índice de maturação (SS/AT) é uma das melhores formas de se avaliar o sabor dos frutos, dando uma boa idéia do equilíbrio entre essas duas variáveis.

Segundo Villanueva et al. (2004), no meloeiro as modificações no sabor são devidas a alterações nos compostos aromáticos, ácidos orgânicos e açúcares solúveis.
Não houve diferença significativa, no que diz respeito ao $\mathrm{pH}$, na polpa de melancia com o aumento dos níveis de nitrogênio, sendo o pH médio dos frutos de 5,34. Esses resultados corroboram com os observados por Morais et al. (2008) visto que não se observou influência da adubação nitrogenada no $\mathrm{pH}$ de frutos de melancia nos níveis de 75 a 300 $\mathrm{kg} \mathrm{ha}^{-1}$ de N. Da mesma forma, Andrade Júnior et al. (2006) estudaram o efeito de diferentes doses de nitrogênio $(0 ; 40 ; 80$; 120 e $160 \mathrm{~kg} \mathrm{ha}^{-1}$ de nitrogênio) em melancieira e concluíram que não houve influência no $\mathrm{pH}$.

A acidez causada pelos ácidos orgânicos é uma característica importante no que se refere ao sabor de muitas frutas. A baixa acidez dos frutos de melancia atrai muitos consumidores cujo valor máximo médio observado se mantém na faixa obtida em outros trabalhos e também dentro do intervalo de pH desejável pelo mercado consumidor (Andrade Júnior et al., 2006).

Os diferentes níveis de nitrogênio influenciaram na produção de açúcares redutores e açúcares solúveis totais, seguindo um modelo quadrático de resposta em nível de significância de 1\% (Figura 3). Os açúcares não redutores também foram afetados significativamente pelos tratamentos resultando num ajuste quadrático $\left(\mathrm{Y}=-0,000005 \mathrm{x}^{2 * *}+0,0011 \mathrm{x} * *\right.$ $\left.+0,272, \mathrm{R}^{2}=0,451\right)$, obtendo-se um máximo de $0,332 \%$ com o uso de $110 \mathrm{~kg} \mathrm{ha}^{-1}$ de $\mathrm{N}$. Este comportamento sugere que as dosagens de $\mathrm{N}$ estabelecidas nos tratamentos foram adequadas para o estudo, mostrando aumentos significativos na produção com as dosagens iniciais, atingindo o ponto de máximo e decrescendo nas maiores dosagens de nitrogênio.

Os principais açúcares presentes em cucurbitáceas são, de forma geral, a glicose, a frutose (AR) e a sacarose (ANR). Os açúcares redutores contribuem com quase $100 \%$ do teor de

A.
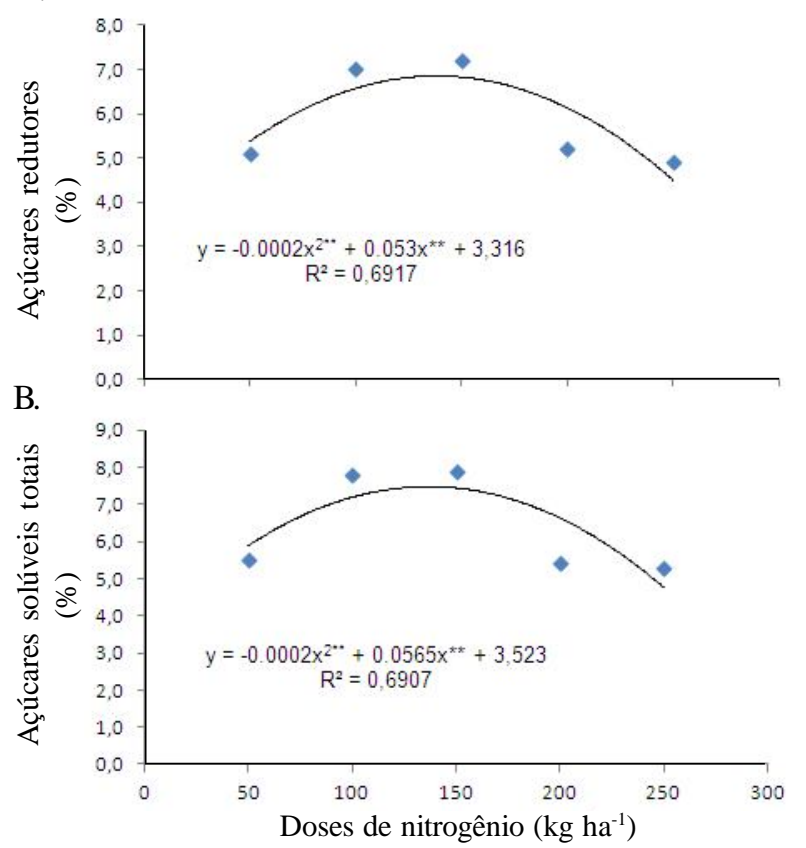

Figura 3. Variação média de açúcares redutores (\%) (A) e açúcares solúveis totais (\%) (B) da polpa de melancia (Citrullus lanatus) em função de níveis de nitrogênio 
açúcares totais na fase inicial de desenvolvimento dos frutos; todavia, a sacarose pode chegar a até $50 \%$ dos açúcares totais na fase final de maturação, com proporção aproximada de $25 \%$ para glicose e $25 \%$ para frutose (Long et al., 2004).

Queiroga et al. (2008) encontraram, estudando número e posição de frutos de melão, valores de $68 \%$ de açúcares não redutores e $31 \%$ para açúcares redutores.

Não foi o que se verificou no presente trabalho uma vez que, em termos gerais, os açúcares redutores representaram, em média, 95\% do açúcar solúvel total, resultando numa polpa mais adocicada, muito embora mais passível de contaminação por serem os açúcares redutores mais assimiláveis e disponíveis para os micro-organismos, podendo levar a uma perda de qualidade pós-colheita, se mal-manejado.

Em relação ao teor de pectina total, ela foi influenciada pelos níveis de nitrogênio seguindo um modelo quadrático $(\mathrm{p}<0,05)$; o valor máximo médio estimado foi de 421,69\% com 76,9 $\mathrm{kg} \mathrm{ha}^{-1}$ de N (Figura 4A).

A pectina total mantém a consistência da fruta conferindo maior firmeza de polpa e, como é parcialmente solúvel, vai diminuindo com o aumento do grau de maturação do fruto,

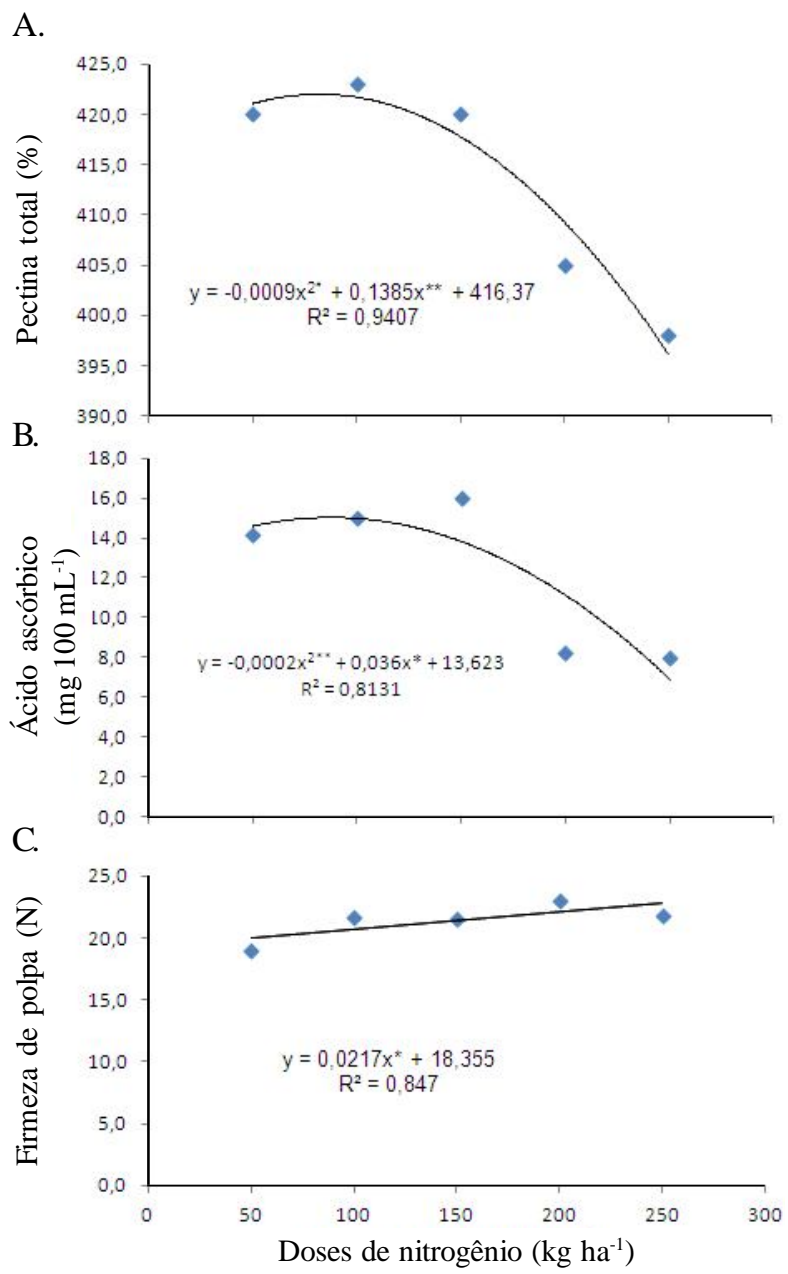

Figura 4. Variação média do teor de pectina total de polpa (\%) (A), ácido ascórbico (mg $100 \mathrm{~mL}^{-1}$ ) (B) e firmeza da polpa (N) (C) de melancia (Citrullus lanatus) em função de níveis de nitrogênio ocasionando o amolecimento da melancia. Portanto, torna-se uma característica indesejável, principalmente quando se consideram as condições de transporte e tempo de prateleira; observou-se, no entanto, que níveis crescentes de nitrogênio estudados resultam na redução da pectina total, podendo conferir menor firmeza aos frutos, com o aumento do grau de maturidade e vida pós-colheita.

Os níveis de nitrogênio influenciaram significativamente ( $\mathrm{p}$ $<0,01)$ o teor de ácido ascórbico seguindo o modelo quadrático de resposta. De modo geral, não foram necessários altos níveis de nitrogênio uma vez que o valor máximo médio estimado de $15,24 \mathrm{mg}$ por $100 \mathrm{~mL}^{-1}$ foi alcançado usando-se $90 \mathrm{~kg} \mathrm{ha}^{-1} \mathrm{de} \mathrm{N}$. Constata-se, portanto, que a aplicação de doses elevadas de $\mathrm{N}$ pode reduzir os teores de ácido ascórbico em frutos de melancia (Figura 4B).

Verificações contrárias também têm sido constatadas com relação ao uso de níveis elevados de nitrogênio. Marinho et al. (2001) verificaram, trabalhando com diferentes fontes (sulfato de amônio e nitrato de amônio) e doses (10, 20 e $30 \mathrm{~g}_{\text {planta }}{ }^{-1}$ mês ${ }^{-1}$ ) de nitrogênio em mamoeiro, que a aplicação de nitrato de amônio promoveu elevado teor de ácido ascórbico.

Foi notório o efeito significativo da firmeza de polpa, influenciado pelos diferentes níveis de adubação nitrogenada, de conformidade com o modelo linear de regressão, quando ocorreu elevação da firmeza de polpa na medida em que se aumentou o nível de adubação nitrogenada (Figura 4C). Corroborando com o resultado, Medeiros (2008) observou aumento da firmeza de polpa de melancia com o aumento das doses de N.

A firmeza de polpa, além de ser um atributo relacionado ao aroma e ao sabor dos frutos, é essencial na vida útil pós-colheita dos mesmos, pois os tornam mais resistentes às injúrias que podem ocorrer durante o transporte e a comercialização (Cardoso Neto et al., 2006).

Não foi constatada influencia significativa no componente de qualidade espessura da casca de frutos de melancia ( $\mathrm{p}>$ 0,05) (Tabela 1). Apesar de não haver diferença significativa a espessura da casca, associada a outros componentes de qualidade, como no caso da firmeza e pectina, vai conferir maior resistência ao transporte do fruto, do manuseio da colheita até a venda ao consumidor final.

Não se verificou influência dos níveis de nitrogênio na relação comprimento/diâmetro, apresentando índice médio de 1,07 o que, de forma geral, é desejado, pois a variedade estudada tem, como característica, o formato do fruto próximo ao esférico (redondo).

\section{CONCLUSÕES}

1. A produção de melancia aumentou significativamente com as doses de nitrogênio, seguindo um modelo quadrático enquanto o número de frutos seguiu um modelo linear decrescente.

2. Os componentes de qualidade da melancia, exceto $\mathrm{pH}$, espessura de casca e relação comprimento/diâmetro, foram influenciados positivamente pela adubação nitrogenada. 


\section{Agradecimentos}

Os autores agradecem ao Conselho Nacional de Desenvolvimento Científico e Tecnológico (CNPq) (Processo 478844/ 2008-5), pelo apoio financeiro a esta pesquisa, e à CAPES, pela concessão da bolsa de estudo.

\section{LITERATURA CITADA}

Andrade Júnior, A. S.; Dias, N.da S.; Figueiredo Júnior, L. G. M.; Ribeiro, V. Q.; Sampaio, D. B. Produção e qualidade de frutos de melancia à aplicação de nitrogênio via fertirrigação. Revista Brasileira Engenharia Agrícola e Ambiental, v. 10, p.836-841, 2006.

Araújo, W. F.; Andrade Júnior, A. S.; Medeiros, R. D.; Sampaio, R. A. Precipitação pluviométrica mensal provável em Boa Vista, Estado de Roraima, Brasil. Revista Brasileira Engenharia Agrícola e Ambiental, v.5, p.563-567, 2001.

Azevedo, B. M.; Bastos, F. G. C.; Viana, T. V. de A.; Rêgo, J. L.; D Ávila, J. H. T. Efeitos de níveis de irrigação na cultura da melancia. Revista Ciência Agronômica, v.36, p.9-15, 2005.

Bleinroth, E. W. Determinação do ponto de colheita. In: Netto, A. G. Melão para exportação: Procedimentos de colheita e pós-colheita. Brasília: FRUPEX, 1994. p.11-21. Série Publicações Técnicas

Cardoso Neto, F.; Guerra, H. O. C.; Chaves, L. H. G. Natureza e parcelamento de nitrogênio na qualidade dos frutos do meloeiro. Revista Caatinga, v.19, p.153-160, 2006.

Carvalho, C. R. L.; Mantovani, D. M.; Carvalho, P. R. N.; Moraes, R. Análises químicas de alimentos. Campinas: Biblioteca do ITAL, 1990, 50p.

Chitarra, M. I. F.; Chitarra, A. B. Pós-colheita de frutos e hortaliças: Fisiologia e manuseio, Lavras: ESAL/FAEPE, 1990. 320p.

Ferreira, D. F. Sisvar, Versão 5.1 (Build 6.0) DEX/UFLA. 2003. <http://www.dex.ufla.br/danielff/prog.htm>. 12 Fev. 2010.

Garcia, L. F.; Sousa, V. A. B. Influência do espaçamento e da adubação nitrogenada sobre a produção da melancia. Revista de la Facultad de Agronomia, v.28, p.59-70, 2002.

Grangeiro, L. C.; Cecílio Filho, A. B. Acúmulo e exportação de macronutrientes pelo híbrido Tide. Horticultura Brasileira, v.22, p.93-97, 2004.

Grangeiro, L. C.; Cecílio Filho, A. B. Acúmulo e exportação de macronutrientes pela melancia sem sementes, híbrido Nova. Horticultura Brasileira, v.23, p.763-767, 2005a.

Grangeiro, L. C.; Cecílio Filho, A. B. Acúmulo e exportação de nutrientes pela cultivar de melancia Mickylee. Revista Caatinga, v.18, p.73-81, 2005b.

IAL - Instituto Adolfo Lutz. Métodos físico-químicos para análise de alimentos. São Paulo: Instituto Adolfo Lutz, 1.ed. 2008,1020p.

IBGE- Instituto Brasileiro de Geografia e Estatística. Sistema IBGE de Recuperação Automática - SIDRA: Banco de dados agregados. Produção agrícola nacional: Lavouras temporárias 2009. <http://www.sidra.ibge.gov.br/bda/tabela/protabl.asp?c=99\& $\mathrm{z}=\mathrm{t} \& \mathrm{o}=11 \& \mathrm{i}=\mathrm{P}>01 \mathrm{Jul} .2010$.
Long, R. L. Walsh, K. B.; Rogers, G.; Midmore, D. J. Sourcesink manipulation to increase melon (Cucumismelo L.) fruit biomass and soluble sugar content. Australian Journal of Agricultural Research, v.55, p.1241-1251, 2004.

Marinho, C. S.; Oliveira, M. A. B. de; Monnerat, P. H.; Vianni, R.; Maldonado, J. F. Fontes e doses de nitrogênio e a qualidade dos frutos do mamoeiro. Scientia Agrícola, v.58, p.345-348. 2001.

McCready, R. M.; Mccomb, E. A. Extraction and determination of total pectic materials in fruit. Analytical Chemistry, v.24, p.1586-1588, 1952.

Medeiros, D. C. Produção e qualidade de melancia fertirrigada com nitrogênio e potássio. Mossoró: UFERSA, 2008. 70p. Tese Doutorado

Medeiros, R. D.; Halfeld-Vieira, B. A. Cultura da melancia em Roraima. Roraima: EMBRAPA; Brasília: Embrapa Informação Tecnológica, 2007. 125p.

Morais, N. B. ; Bezerra, F. M. L.; Medeiros, J. F. de; Chave, S. W. P. Resposta de plantas de melancia cultivadas sob diferentes níveis de água e de nitrogênio. Revista Ciência Agronômica, v.39, p.369-377, 2008.

Mousinho, E. P.; Costa, R. N. T.; Souza, F. da; Gomes Filho, R. R. Função de resposta da melancia à aplicação de água nitrogênio para as condições edafoclimáticas de FortalezaCE. Irriga, v.8, p.264-272, 2003.

Nelson, N. A. Photometric adaptation of the Somogyi method for the determination of glucose. Journal of Biological Chemistry, v.153, p.375-380, 1944.

Purquerio, L. F. V.; Cecílio Filho, A. B. Concentração de nitrogênio na solução nutritiva e número de frutos sobre a qualidade de frutos de melão. Horticultura Brasileira, v.23, p.831-836, 2005.

Purquerio, L. F. V.; Cecílio Filho, A. B.; Barbosa, J. C. Efeito da concentração de nitrogênio na solução nutritiva e do número de frutos por planta sobre a produção do meloeiro. Horticultura Brasileira, v.21, p.186-191, 2003.

Queiroga, R. C. F.; Puiatti, M.; Fontes, P. C. R.; Cecon, P. R. Produtividade e qualidade de frutos de meloeiro variando número de frutos e de folhas por planta. Horticultura Brasileira, v.26, p.209-215, 2008.

Taiz, L.; Zeiger, E. Fisiologia vegetal. 3.ed. PortoAlegre: Artmed, 2004. 719p.

Valantin, M.; Vaissiere, B. E; Gary, C.; Robin, P. Source-sink balance affects reproductive development and fruit quality in cantaloupe melon. Journal of Horticultural Science \& Biotechnology, v.81, p.105-117, 2006.

Vidigal, S. M.; Pacheco, D. D.; Costa, E. L. da; Facion, C. E. Crescimento e acúmulo de macro e micronutrientes pela melancia em solo arenoso. Revista Ceres, v.56, p.112-118, 2009.

Villanueva, M. J.; Tenório, M. D.; Esteban, M. A.; Mendonza, M. C. Compositional changes during ripening of two cultivars of muskmelon fruits. Food Chemistry, v.87, p.179185, 2004. 